\title{
Impacts of Wheat Powdery Mildew on Grain Yield \& Quality and Its Prevention and Control Methods
}

\author{
Hongyun Gao ${ }^{1,2}$, Jishan $\mathrm{Niu}^{3}$, Suoping $\mathrm{Li}^{2,}$, \\ ${ }^{1}$ Department of Life Sciences, Zhengzhou Normal University, Zhengzhou, China \\ ${ }^{2}$ Key Laboratory of Plant Stress Biology, Henan University, Kaifeng, China \\ ${ }^{3}$ College of Agronomy, Henan Agricultural University, Zhengzhou, China
}

\section{Email address:}

ghy7877@163.com (Hongyun Gao), jsniu@263.net (Jishan Niu), lisp369@163.com (Suoping Li)

${ }^{*}$ Corresponding author

\section{To cite this article:}

Hongyun Gao, Jishan Niu, Suoping Li. Impacts of Wheat Powdery Mildew on Grain Yield \& Quality and Its Prevention and Control Methods. American Journal of Agriculture and Forestry. Vol. 6, No. 5, 2018, pp. 141-147. doi: 10.11648/j.ajaf.20180605.14

Received: August 3, 2018; Accepted: August 31, 2018; Published: September 28, 2018

\begin{abstract}
As one of the major foliar diseases, wheat powdery mildew caused by Blumeria graminis f. sp. tritici (Bgt) affects photosynthesis of nutrient organs, such as stems and leaves, causing a reduction in production to varying degrees. In recent years, it has been found that powdery mildew can also affect grain quality, including nutritional quality and processing quality. Powdery mildew can cause changes of grain protein content, its components, starch content and ratio of amylose to amylopectin, and it can also cause changes of grain volume weight, flour falling number and viscosity, extensograph and farinograph parameters, etc. The studies have also found that powdery mildew can increase the expression level of molecular chaperones and enzymes relating to protein synthesis, which led to the rise in protein synthesis. And glycolysis-related proteins also show high expression levels in grains from infected wheat, which implies that glycolysis is very active and further results in the depletion of starch content. These results show that the research on the mechanism of quality change caused by disease has also made some progress. This paper includes five parts: the first part introduces the infection characteristics of wheat powdery mildew. The second part elaborates the change of wheat yield caused by powdery mildew and its influence mechanism. In the third part, the effect of powdery mildew on wheat quality and its molecular mechanism are discussed. The fourth part analyzes the four prevention and control ways from cultivating disease-resistant varieties, strictly controlling the use of fungicides, advocating spraying silicate and biological control. Finally, the last part is a prospect where the effect of wheat powdery mildew on quality and its molecular mechanism and the comprehensive pollution-free control system of wheat powdery mildew are discussed. The paper aims to provide the basis for the research of quality physiology and pollution-free control of wheat powdery mildew.
\end{abstract}

Keywords: Wheat, Powdery Mildew, Yield, Quality, Prevention, Control Methods

\section{Introduction}

In recent years, wheat powdery mildew has occurred frequently due to decreased resistance of wheat varieties, increased planting density and climate change, etc. [1]. During wheat heading period and flowering period, wheats are often attacked by powdery mildew, which seriously result in yield reduction [2-5]. Studies on the distribution and infection characteristics of wheat powdery mildew are extensive $[2,6]$. And there have been many studies on the effects of the disease on yield and its physiological mechanisms [7, 8]. With the development of wheat quality ecological research, the influence of disease on grain quality has been paid more and more attention. Studies on the effect of powdery mildew on wheat quality and its mechanism have been deepened gradually [3-5]. The research on comprehensive prevention and control of wheat powdery mildew has been carried out step by step, such as cultivating disease-resistant varieties, looking for alternatives to fungicides, spraying silicate, adopting biological control [9-11]. The infection characteristics, the impacts and their mechanisms on grain yield and quality, as well as the prevention and control 
methods of wheat powdery mildew are analyzed in turn in this paper. Finally, some suggestions on the study of powdery mildew influence on quality and the pollution-free prevention of powdery mildew are put forward. The purpose of this review is to provide reliable reference data and theoretical support for the further study of wheat powdery mildew.

\section{Infection Characteristics of Wheat Powdery Mildew}

Wheat powdery mildew is serious in cold and humid regions of Asia, Africa and Europe and the United States. With the popularization and application of dwarf and semi-dwarf wheat varieties, powdery mildew is becoming more and more serious, due to the increase of planting density and nitrogen application, improvement of irrigation conditions and greenhouse effect [6]. Powdery mildew mainly infects leaves, but can also infect leaf sheath, stem and ear when serious. It overwinters with mycelium lurking on the lower leaf or leaf sheath of the plant. Through conidia and closed capsule on the surface of the stem and leaves, the conidiospores can be transmitted from a long distance by high air flow, which makes the disease epidemic stronger. The spores spread to the infected plant, and when they met the appropriate conditions in a short time (1-7d), the bud tube can be germinated, and the top of the bud tube is enlarged to form the appressorium. The appressorium produces the haustoria by invagination of the plasmalemma, and directly penetrates the surface of a host nutrient organ or spike [12], specially infests epidermal cells, and the formed haustoria can absorb host nutrients [13]. The optimum temperature of wheat powdery mildew was $10 \sim 20^{\circ} \mathrm{C}$. When the air humidity is high, it is beneficial to the formation and invasion of spores, so the disease is aggravated. However, when the humidity is too large and the rainfall is too much, it is not conducive to the formation and propagation of conidia. Sunlight suppresses spore germination [14], so when wheat planting density is too big, ventilation is poor, the infection can be serious. Excessive application of nitrogen fertilizer, excessive irrigation, or the combination of the two, is conducive to the propagation and infection of pathogens, the infection is aggravated. When the condition of water and fertilizer is good, it is easy to appear the phenomenon of population depression, and thus prone to infection. Plant growth is weak and disease resistance is decreased when fertility is insufficient and soil is dry. In the Huang-Huai wheat-growing region of China, the high incidence of wheat powdery mildew usually occurs from late April to mid-May, which is at the critical stage of wheat heading period to grain filling period.

\section{Effects of Wheat Powdery Mildew on Yield and Physiological Mechanism}

\subsection{Impacts on Yield}

The rate of reduction in output of powdery mildew infection varies with the occurrence time and the severity of the disease. With the infection occurring at seedling stage, the growth and development of wheat are hindered and the plants die when powdery mildew is severe. With the infection occurring at tillering stage, powdery mildew could inhibit the development of wheat roots and reduce the formation of tillers [2]. The occurrence of powdery mildew at heading and flowering stages can cause the decrease of the number of grains per ear [15], grain fullness and grain weight [16]. Studies on wheat near-isogenic lines [17] show that when powdery mildew is serious, the yield loss is serious, reaching 34\%. Wheat field tests using a susceptible variety "Yanzhan 4110" and a moderate susceptibility "Yu'nong 416", show that wheat production decreases by $26.2 \%$ and $15.8 \%$ respectively [18]. Field experiments are also carried out on another susceptible variety "Xi'nong 979" and one moderate susceptibility variety "Zhoumai 18", the results show that the incidence of powdery mildew is moderate and the yield loss is less than $10 \%$ [4].

\subsection{Physiological Mechanism of Powdery Mildew}

Previous studies on the mechanism of powdery-mildew-induced reduction mostly focus on the physiological and biochemical changes of the stems and leaves. When powdery mildew covers the surface of stems, leaves and glumes etc., the photosynthetic area decreases significantly [7], chlorophyll degrades [8], the green islands appeares $[7,8]$, the expression of defense-related proteins was different $[19,20]$, and the apparent quantum yield and photosynthetic rate of photosynthesis decreases [21]. All of these reduce the synthesis and accumulation of homogenates in the affected nutritional organs. Meanwhile, as powdery mildew is a living parasitic fungus, it relies on host metabolism to provide carbohydrates, amino acids and inorganic nutrients, therefore, the metabolic burden of the host tissue increases after infection. Studies show that activities of all types of invertase increase in the infected tissue [22], thus a large number of simple sugars are formed available to the pathogens, which results in a decrease in the amount of photosynthate transported from susceptible leaves to grains. All of these affections make changes in source-bank balance in wheat plants. In addition, there are reports of the inhibition of root growth and physiological activity of wheat under infectious conditions [23]. Thus, the interaction between wheat plants and Bgt is a complex process, the sporophyte of Bgt acts as an additional bank, competing with the host bank (roots and grains), and this results in changes in the production, transport and distribution balance of assimilation products in wheat plants [22]. Proteomics studies on the metabolism of grains show that the transformation of soluble sugar into starch is inhibited after the infection of powdery mildew, and the expressions of key enzymes in starch synthesis ( $\alpha-1,4$-phosphorylase, sucrose synthase) decrease. The reductions of these enzymes might inhibit the synthesis of starch, especially amylopectin, and reduce the grain starch content and yield [5]. Recent research suggests that the abundance of ADPG pyrophosphorylase decreases in grains from infected plants [24], and the decrease may make the 
starch synthesis inadequate. It is also found that the expressions of phosphoglycerate mutase, 3-phosphoglycerate kinase and UTP-glucose-1-phosphate uridylyltransferase increase [24]. It indicates that glycolysis is very active, which leads to the consumption of carbohydrate in grains [24].

\section{Impacts of Wheat Powdery Mildew on Quality and Its Molecular Mechanism}

\subsection{Impacts on Quality}

The influence of wheat powdery mildew on grain quality has aroused widespread concern. At present, no common quality change effect has been found, because the infection of powdery mildew is a dynamic process, and grain quality is a comprehensive character. Early studies indicate that the protein content of flour decreases after wheat near-isogenic line "Chancellor" is infected with powdery mildew, and the reduction is negatively correlated with the severity of powdery mildew [17]. In recent years, studies on the effect of powdery mildew on quality have been carried out gradually $[3-5,18$, 24]. Among them, some reaches the same conclusion as Johnson's study [17], such as Cao' research [4] showing that powdery mildew causes the grain protein content to decrease under the stress of powdery mildew by using the high susceptible wheat variety "Jingshuang 16". And Feng' research [18] also shows the grain protein contents of high susceptible cultivar "Yanzhan 4110" and moderate susceptibility cultivar "Yu'nong 416" decreased by Bgt affection. While the conflicting report is made that powdery mildew could make grain total protein content increase by using another susceptible variety "Xi'nong 979" and one moderate susceptibility variety "Zhoumai 18" [4]. Recently, further research also shows that grain protein content increases by using the same susceptible variety "Xi'nong 979" [24]. The above studies on the effect of powdery mildew on grain total protein content have different conclusions. It is speculated that the experimental treatment adopted by different research groups is different, and different disease severity degrees of different wheat varieties are different. The studies also find that powdery mildew infection results in a significant increase in grain storage protein content [4, 18, 24]. The starch content, especially the amylopectin content decreases significantly and the ratio of amylose to amylopectin increases $[5,24]$. These results provide a deeper understanding of the change of grain quality after wheat powdery mildew infection.

In recent years, the research of wheat powdery mildew on the quality of flour processing has increased gradually $[18,25]$. Powdery mildew can reduce grain volume weight first $[16,25]$, that is, grain fullness is decreased. Second, powdery mildew can increase the flour falling number [18, 25], which shows that grain alpha-amylase activity decreases, and this trend is consistent with the decrease in starch content [4]. Third, powdery mildew can cause changes in flour viscosity. Some research points out that the viscosity increases because of powdery mildew infection [25]. Other study has found that the viscosity decreases with the increase of the severity of powdery mildew [18]. The reason why the two conclusions are not consistent is inferred that the experimental treatments are different. In addition, the rheological parameters of dough, such as extensograph and farinograph parameters also increase with powdery mildew $[18,25]$. There have also been changes of other quality indicators, including SDS sedimentation value, swelling power [25]. The trends of different quality parameters vary differently in different quality varieties with different severities [18, 25]. Thus, further relevant research is needed.

Therefore, it might be seen that wheat powdery mildew affects the formation of grain storage reserves, and then affects the quality. As a fungal disease, powdery mildew is relatively complex and involves the interaction between small physiological species of pathogens and different wheat varieties, and it is closely related to the degree of disease, the time of onset and the quality type of wheat. The grain quality is influenced by many factors, such as heredity and environment, and the change is also very complicated. There is much research space for quality change and its influence mechanism under disease condition.

\subsection{Molecular Mechanism}

The difference of metabolic protein expression in grains infected with wheat powdery mildew is analyzed by differential proteomics [4, 24]. The expressions of grain proteases and molecular chaperones (including peptidylprolyl isomerase, cyclophilin A-2 and GTPase ObgE) involved in protein synthesis show up or newly appear, and this was consistent with the increase of grain protein content in the same period [4, 24]. Comparative proteomics analysis also shows that the significant elevated triticin, serpin and HMW-GS may be related to the improvement of gluten quality [24]. Gao et al [4] speculate that there may be two mechanisms for the increase of grain protein content, one is the passive increase of protein content percentage in wheat grain caused by yield reduction, that is, the reduction of starch accumulation could cause protein enrichment. Second, the activity of the protein-synthesis-related enzymes in wheat grains are activated or enhanced, thus the protein synthesis is promoted to a certain extent [4]. Recent studies have also pointed out that the decrease in the amount of expression of AGPase in grains from infected plants may make the starch synthesis inadequate [24]. It is also found that powdery mildew could activate the glycolysis pathway in the grain during the filling period, showing an increase in the amount of expression of enzymes involved in the pathway, including phosphoglycerate mutase, cytosolic 3-phosphoglycerate kinase, and UTP-glucose-1-phosphate uridylyltransferase, leading to the consumption of carbohydrate in grains [24]. Therefore, it is inferred that grain protein content may change dynamically with the degree of powdery mildew, which needs to be further studied. The study also finds that NBS-LRR-type RGA and GTPase ObgE increase [4], and 1-Cys peroxiredoxin PER1 increases as well [24], which reveals that leaf infection with powdery mildew can lead to the interaction between 
proteins induced by resistant proteins in the grain [4].

\section{Prevention and Control of Wheat Powdery Mildew}

At present, the research and exploration of effective wheat powdery mildew prevention and control technology has become one of the key issues in physiological and ecological research. The prevention and control of wheat powdery mildew should not merely continue to strengthen the basic prevention and control, and disease resistant varieties should also be selected according to the ecological characteristics of different wheat areas, reasonable arrangement of sowing quantity, formula fertilization, proper irrigation. The prevention and control should combine with the control of the fungal source during wheat seedling stage in autumn as well, to reduce the occurrence and prevalence of powdery mildew. Besides, there could also be following four ways to carry out comprehensive prevention and control.

\subsection{Cultivation of Disease Resistant Varieties}

It is the most economical, safe and effective way to prevent and control wheat powdery mildew by broadening wheat resistance source, polymerizing disease resistant genes and spreading disease resistant varieties [26, 27]. In recent years, researchers have isolated and localized several powdery mildew resistance genes [28, 29], and developed some new varieties of powdery mildew resistance [30, 31]. However, due to the change of physiological species of pathogen, the resistant varieties developed in production practice generally lose resistance in 3 to 5 years. A wider genetic range of varieties resistant to powdery mildew are needed, and resistant resources are screened from exotic species, the introduction of transgenic technology into wheat has become the primary goal of powdery mildew resistance breeding (Shenghao Zou, 2018) [32].

\subsection{Control the Use of Fungicides}

Spraying fungicides is an important disease control strategy in the absence of durable and effective varieties of powdery mildew resistance [33]. There are many kinds of fungicides to prevent and cure powdery mildew, including triazolone, flutriafol, benzimidazole, diniconazole and thiocarbamate [34]. In addition, methoxy acrylate fungicides have a good effect on powdery mildew. It has been pointed out that there is interaction resistance between methoxy acrylate fungicides, such as metominostrobin, pyrametostrobin and azoxystrobin [34]. Fungicides with different mechanisms are used in rotation in production. According to the research, propiconazole and flusilazole can be used alternately with triazolone, which has good control effect on wheat powdery mildew, and is an effective measure to ensure high and steady yield of wheat [34]. However, appropriate amount of fungicides should be sprayed [35]. Excessive or repeated use of fungicides can lead to poor wheat quality, including reduction of protein content, sulfur content, threshold value and bread volume [37]. It can also lead to an increase in fungicide residues. There are also technical, environmental and toxic risks. The synthetic chemical fungicides shall not be permitted or strictly restricted in the pollution-free integrated control system. It is urgent to find new, effective and environmentally compatible ways to control powdery mildew.

\subsection{Initiating Spray Silicate}

According to the research, spraying silicate can improve the peroxidase activity and lignin content of wheat susceptible varieties, reduce the powdery mildew index of susceptible plants [38], and improve resistance of wheat plants to powdery mildew $[10,11]$. The study of Bélanger shows that silicon can inhibit the growth of powdery mildew in epidermal cells, resulting in poor development of the haustorium and lower infection level [39]. Other study also shows that silicate could enhance or activate the defense mechanism of wheat leaf epidermal cells, and it could reduce the formation of spore germination and attachment cells [40]. After the application of silicate, the epidermis of wheat leaves has an allergic reaction, producing phenolic substances that can cause the disintegration of conidium chains, and thus wheat is prevented from being infected by powdery mildew [39, 41]. And it can regulate the soil $\mathrm{pH}$ and improve the soil [9]. It can be seen that spraying silicate can improve the resistance of wheats. Recent research shows that the relationships between the applied doses of silicon and decreasing Bgt expansion in foliar surfaces are also obvious [38].

\subsection{Biological Control}

In recent years, the biological prevention and control of powdery mildew has attracted more and more attention. Some microorganisms that are beneficial to plants are selected and used alone or combined with some existing substances in nature, to act as a natural antagonist of pathogen to resist different plant pathogen [33]. It is found that wheat leaves can induce acquired resistance after inoculation with barley powdery mildew. A yeast-like saprophytic fungus Pseudozyma flocculosa has been shown to be an effective inhibitor of powdery mildew [42]. The rhizome of Zingiber officinale Roscoe and the leaves of Reynoutria sacchaliensis L. can also control powdery mildew effectively [43]. And a biological control agent, yeast Rhodosporidium kratochvilovae and Cryptococcus laurentii, or yeast similar fungi Aureobasidium pullulans combined with calcium silicate or sulfur, can also effectively control powdery mildew, and increase the yield of durum wheat [33]. It is found that the Bacillus subtilis had an anti-powdery mildew resistance during the period before the conidial germination of powdery mildew [44]. In addition, a gram-negative bacterium, Sphingomonas, can also be used as a biological control agent to reduce the severity of powdery mildew [45]. Studies of biological control mechanisms suggest that yeast or its analogues can degrade plant antitoxins [33]. Other studies also prove that the Bacillus subtilis could produce a kind of lipid peptide substance (turin) which can effectively inhibit the 
germination of conidia [44]. With the further development of comprehensive pollution-free prevention and control technology, biological control combined with other measures, such as reasonable planting, formula fertilization, timely watering and reducing the source of powdery mildew can reduce the occurrence and prevalence of powdery mildew and has a wide application prospect.

\section{Prospect}

\subsection{The Effect of Wheat Powdery Mildew on Quality and Its Molecular Mechanism Need Further Study}

Although there are some studies on the effect of powdery mildew on grain quality and its molecular mechanism, due to the differences between varieties and the complexity of disease, the related researches focus more on analyzing the changes of protein content and components in grain [4, 18,24], changes of soluble sugar metabolism and starch components in kernel [5]. While the analysis of other components has not been involved, nor has it been analyzed whether toxins are produced and accumulated in grain, what types of toxins are present and what the harm is. And the effect of powdery mildew on processing quality is limited to the preliminary comparison of the rheological parameters of dough, such as extensograph and farinograph parameters, viscosity and so on $[18,25]$. The study on the molecular mechanism of the effect on quality involves the difference of metabolic protein expression in grain development under the condition of susceptibility to disease $[4,24]$. But the related research is mainly about the change of protein expression level, while the researches on the changes of mRNA level and some key enzymes activities are lack. And the related studies on the change of specific metabolic pathway and its deep mechanism need to be strengthened. In the future, if we can combine the changes of key enzymes activities, we can study the difference of metabolism in seed development under the stress of powdery mildew. Combining quality analysis will be helpful to reveal the mechanism of powdery mildew's influence on grain quality, and to control wheat quality. And it will lay the foundation for further clarification of the wheat-fungi interaction.

\subsection{Research on Comprehensive Pollution-Free Control System of Wheat Powdery Mildew Should Be Strengthened Gradually}

At present, spraying fungicides is the main measure to prevent and control powdery mildew in agricultural production, but at the same time, people are very concerned about food safety and environmental protection. Therefore, choosing efficient and low-toxic fungicides, paying attention to the rotation use of fungicides, reducing unnecessary prevention and control are needed to reduce environmental pollution and pesticide residues. Comprehensive use of other agricultural measures, such as breeding resistant varieties, reasonable fertilization, reasonable irrigation, silicate application combined with biological control of wheat powdery mildew control system is gradually improved. Among them, silicate has a broad application prospect for prevention and control of powdery mildew, and its comprehensive prevention and control technology research needs to be further developed [33]. There are two views on the mechanism of silicon control, one is that silicon deposition in fungal infection site or epidermal wound increases the mechanical strength of cell wall. Another view is that silicon can induce plants to produce a series of resistant antagonistic pathogenic fungi [10]. These studies focus on physiology or morphology, while the molecular mechanisms of silicate control need to be further studied. The mechanism of action and spraying technology for prevention and treatment of wheat powdery mildew by silicate should be strengthened. In recent years, it has been found that the use of microbial agents which are antagonistic to powdery mildew is also an effective control method. For example, biological control of yeast and its similar fungus [33], Sphingomonas [45] or Bacillus subtilis [44] can effectively prevent powdery mildew and increase yield, but the control effect of infected plants is poor [45]. The study also finds that the use of biological control agents alone, or inorganic salts such as silicate, is less effective than the use of both measures. The most effective measures to reduce disease severity and increase yield are biological control agents combined with calcium silicate or sulfur [33]. In the integrated agricultural system, the use of biological control agents combined with a few additives (silicon, sulfur, etc.) is a potentially effective measure to prevent powdery diseases, which has great potential to increase production.

\section{Conflict of Interest}

The authors declare that they do not have any conflict of interest.

\section{Acknowledgements}

This study was supported by Funding Plan for Key Scientific Research Projects in Colleges and Universities of Henan Province (19A210025).

\section{References}

[1] T. Miedaner and K. Flath (2007). Effectiveness and environmental stability of quantitative powdery mildew (Blumeria graminis) resistance among winter wheat cultivars [J]. Plant Breeding, 126(6): 553-558.

[2] J. S. Niu, H. C. Wang, D. F. Hong, et al (2006). Advance in studies on molecular basis for wheat powdery mildew resistance [J]. Journal of Henan Agricultural University, 40(6): 678-682. (in Chinese)

[3] X. R. Cao, Y. L. Zhou, X. Y. Duan, et al (2009). Estimation of the effects of powdery mildew on wheat yield and protein content using hyperspectral remote sensing [J]. Acta Phytophylacica Sinica, 36(1): 32-36. 
[4] H. Y. Gao, D. X. He, J. S. Niu, et al (2014). The effect and molecular mechanism of powdery mildew on wheat grain prolamins $[\mathrm{J}]$. The Journal of Agricultural Science, 152(2):239-253.

[5] H. Y. Gao, J. S. Niu, X. W. Yang, et al (2014). Impacts of powdery mildew on wheat grain sugar metabolism and starch accumulation in developing grains $[\mathrm{J}]$. Starch/Stärke, 66(11-12): 947-958.

[6] J. M. Wang, H. Y. Liu, H. M. Xu, et al (2012). Analysis of differential transcriptional profiling in wheat infected by Blumeria graminis f. sp. tritici using GeneChip [J]. Molecular Biology Reports, 39(1): 381-387.

[7] D. R. Walters, N. McRoberts, B. D. L. Fitt (2008). Are green islands red herrings? Significance of green islands in plant interactions with pathogens and pests [J]. Biological Reviews, 83(1): 79-102.

[8] J. Kuckenberg, I. Tartachnyk, G. Noga (2009). Temporal and spatial changes of chlorophyll fluorescence as a basis for early and precise detection of leaf rust and powdery mildew infections in wheat leaves [J]. Precision Agriculture, 10(1): 34 44.

[9] M. C. Provance-Bowley, J. R. Heckman, E. F. Durner (2010). Calcium silicate suppresses powdery mildew and increases yield of field grown wheat [J]. Soil Science Society of America Journal, 74(5): 1652-1661.

[10] Y. F. Yang, Y. C. Liang, Y. S. Lou, et al (2003). Influences of silicon on peroxidase, superoxide dismutase activity and lignin content in leaves of wheat ( Tritium aestivum L .) and its relation to resistance to powdery mildew. Scientia Agricultura Sinica, 36(7): 813-817.

[11] T. Deliopoulos, P. S. Kettlewell, M. C. Hare (2010). Fungal disease suppression by inorganic salts: A review [J]. Crop Protection, 29(10): 1059-1075.

[12] R. Bruggmann, O. Abderhalden, P. Reymond, et al (2005). Analysis of epidermis- and mesophyll-specific transcript accumulation in powdery mildew-inoculated wheat leaves $[\mathrm{J}]$. Plant Molecular Biology, 58(2): 247-267.

[13] K. Mendgen and M. Háhn (2002). Plant infection and the establishment of fungal biotrophy [J]. Trends in Plant Science, 7(8): 352-356.

[14] C. N. Austin, G. G. Grove, J. M. Meyers, et al (2011). Powdery mildew severity as a function of canopy density: associated impacts on sunlight penetration and spray coverage. American Journal of Enology \& Viticulture, 62 (1): 23-31.

[15] R. A. Serrago, R. Carretero, M. O. Bancal, et al (2011). Grain weight response to foliar diseases control in wheat (Triticum aestivum L.)[J]. Field Crops Research, 120(3): 352-359.

[16] C. F. Morris and S. P. Rose. Wheat. In: Henry RJ and Kettle PS (Eds.), Cereal Grain Quality [M]. Chapman and Hall, London, 1996, pp.160-224.

[17] J. W. Johnson, P. S. Baenziger, W. T. Yamazaki, et al (1979). Effects of powdery mildew on yield and quality of isogenic lines of 'Chancellor' wheat [J]. Crop Science, 19(3): 349-352.

[18] W. Feng, X. Li, W.D. Liu, et al (2014). Effects of powdery mildew infection on grain quality traits and yield of winter wheat. Journal of Triticeae Crops, 34(12): 1706-1712.
[19] F. Chen, Y. Yuan, Q. Li, et al (2007). Proteomic analysis of rice plasma membrane reveals proteins involved in early defense response to bacterial blight [J]. Proteomics, 7(9): 1529-1539.

[20] Q. Li, X. M. Chen, D. Li, et al (2011). Differences in protein expression and ultrastructure between two wheat near-isogenic lines affected by powdery mildew [J]. Fiziologiya Rastenii, 58(4): 686-695.

[21] D. P. Wright, B. C. Baldwin, M. C. Shephard, et al (1995). Source-sink relationships in wheat leaves infected with powdery mildew. I. Alterations in carbohydrate metabolism [J]. Physiological and Molecular Plant Pathology, 47(3-4): 237253.

[22] P. N. Sutton, M. J. Gilbert, L. E. Williams, et al (2007). Powdery mildew infection of wheat leaves changes host solute transport and invertase activity [J]. Physiologia Plantarum, 129(4): 787-795.

[23] X. Y. Deng, J. W. Li, Z. Q. Zhou, et al (2010). Cell death in wheat roots induced by the powdery mildew fungus Blumeria graminis f. sp.tritici [J]. Plant and Soil, 328(1-2): 45-55.

[24] J. Li, X. H. Liu, X. W. Yang, et al (2018). Proteomic analysis of the impacts of powdery mildew on wheat grain $[\mathrm{J}]$. Food Chemistry, 261 (4): 30-35.

[25] H. Y. Gao (2012). Influence of powdery mildew on quality and its molecular mechanism in wheat (Triticum aestivum L.) [D]. Doctoral dissertation of Henan agricultural university, Zhengzhou city, Henan province, China.

[26] H. Q. Zhang (2008). Research advances in molecular breeding of powdery mildew resistance of wheat. Chinese Journal of Eco-Agriculture, 16(4): 1060-1066.

[27] F. J. Song, M. G. Xiao, J. Huang, et al (2012). Inheritance of Resistance to Powdery Mildew in 12 Wheat Varieties (Lines). Acta Agronomica Sinica, 38(7): 1339-1345.

[28] H. X. Xu, G. Q. Yao, L. Xiong, et al (2008). Identification and mapping of pm2026: A recessive powdery mildew resistance gene in an einkorn (Triticum monococcum L.) accession $[\mathrm{J}]$. Theoretical and Applied Genetics, 117(4): 471-477.

[29] R. Q. Zhang, B. X. Sun, J. Chen, et al (2016). Pm55, a developmental-stage and tissue-specific powdery mildew resistance gene introgressed from Dasypyrum villosum into common wheat. Theor Appl Genet, 129(10):1975-1984.

[30] W. G. Xu, C. X. Li, L. Hu, et al (2010). Molecular mapping of powdery mildew resistance gene PmHNK in winter wheat (Triticum aestivum L.) cultivar Zhoumai 22 [J]. Molecular Breeding, 26(1): 31-38.

[31] C. X. Li, W. G. Xu, R. Guo, et al (2018). Molecular marker assisted breeding and genome composition analysis of Zhengmai 7698 , an elite winter wheat cultivar. Scientific Reports, 8(1):322-330.

[32] S. H. Zou, H. Wang, Y. W. Li, et al (2018). The NB-LRR gene Pm60 confers powdery mildew resistance in wheat. New Phytologist, 218(1): 298-309.

[33] F. D. Curtis, V. D. Cicco, G. Lima (2012). Efficacy of biocontrol yeasts combined with calcium silicate or sulphur for controlling durum wheat powdery mildew and increasing grain yield components [J]. Field Crops Research, 134(1): 36-46. 
[34] L. Yang, Y. L. Zhou, X. Y. Duan, et al (2013). Sensitivity of Blumeria graminis f. sp. tritici isolates to triadimefon and fenpropidin in China in 2011. Acta Phytopathologica Sinica, 43(4): $430-434$.

[35] H. F. Gao, Y. Nurziya, G. K. Li (2013). Control efficacy of several fungicides to wheat powdery mildew. Xinjiang Agricultural Sciences, 50(7): 1260-1264.

[36] Y. L. Tang, C. S. Li, C. Wu, et al (2012). Effect of spraying chemical patterns on grain yield, quality and profit of wheat. Journal of Triticeae Crops, 32(1): 157-162.

[37] R. E. Ruske, M. J. Gooding, B. J. Dobraszczyk (2004). Effects of triazole and strobilurin fungicide programmes, with and without late-season nitrogen fertiliser, on the baking quality of Malacca winter wheat [J]. Journal of Cereal Science, 40(1): 18.

[38] C. A. Moldes, O. F. L. Filho, L. J. Merini, et al (2016). Occurrence of powdery mildew disease in wheat fertilized with increasing silicon doses: a chemometric analysis of antioxidant response. Acta Physiol Plant, 38(8):206-214.

[39] R. R. Bélanger, N. Benhamou, J. G. Menzies (2003). Cytological evidence of an active role of silicon in wheat resistance to powdery mildew (Blumeria graminis f. $\mathrm{sp}$ tritici)[J]. Phytopathology, 93(4): 402-412.

[40] T. Kanto, K. Maekawa, M. Aino (2007). Suppression of conidial germination and appressorial formation by silicate treatment in powdery mildew of strawberry [J]. Journal of General Plant Pathology, 73(1): 1-7.
[41] W. Rémus-Borela, J. G. Menziesb, R. R. Bélangera (2005). Silicon induces antifungal compounds in powdery mildew-infected wheat $[\mathrm{J}]$. Physiological and Molecular Plant Pathology, 66(3): 108-115.

[42] W. R. Jarvis, J. A. Traquair, R. R. Bélanger. Perspectives on the development of Sporodex: fungal biocontrol for powdery mildew in greenhouse crops. In: Vincent $\mathrm{C}$, Goettel $\mathrm{M}$, Lazarovits G (Eds). Biological Control: A Global Perspective [M]. UK: CABI Publishing, 2007: 224-233.

[43] L. Vechet, L. Burketova, M. Sindelarova (2009). A comparative study of the efficiency of several sources of induced resistance to powdery mildew (Blumeria graminis f. $\mathrm{sp}$ tritici) in wheat under field conditions [J]. Crop Protection, 28(2): 151-154.

[44] C. A. Dunlap, D. A. Schisler, N.P. Price, et al (2011). Cyclic lipopeptide profile of three Bacillus subtilis strains; antagonists of Fusarium head blight [J]. Journal of Microbiology, 49 (4): 603-609.

[45] U. Wachowska, W. Irzykowski, M. Jędryczka, et al (2013). Biological control of winter wheat pathogens with the use of antagonistic Sphingomonas bacteria under greenhouse conditions $[\mathrm{J}]$. Biocontrol Science and Technology, 23(10): $1110-1122$. 